\title{
A NOTE ON HÖLDER'S INEQUALITY FOR MATRIX-VALUED MEASURES
}

\author{
SAMANTHA LEORATO
}

Abstract. Following [1], we prove a version of Holder's inequality for matrix-valued measures. As corollaries, an integral version of moment type inequalities in [3] and Minkowski inequality are derived.

Mathematics subject classification (2010): 46L53, 47LXX.

Keywords and phrases: Matrix-valued probability measures, Jensen's inequality, Hölder's inequality.

\section{REFERENCES}

[1] D. R. FARENICK AND F. ZHou, Jensen's inequality relative to matrix-valued measures, J. Math. Anal. Appl. 327 (2007) 919-929.

[2] F. HiaI, Matrix Analysis: Matrix Monotone Functions, Matrix Means, and Majorization Interdisciplinary Information Sciences 16, no. 2 (2010) 139-248.

[3] J. PeČARIĆ, Power matrix means and related inequalities, Mathematical Communications 1 (2) (1996) 91-110. 